\title{
AUTOMATIC PIPE-WIRE CUTTING MACHINE
}

\author{
Mr. D. G. Gahane, Prachi Katole, Priyanka Naidu, Ruchita Dhoke, Sushama Kore \\ Engineering Students, E\&TC Engineering Department, \\ Priyadarshini College of Engineering, Nagpur, Maharashtra, India
}

\begin{abstract}
Pipe/wire cutting operation is very unique importance in pipe or wire extruding industries. In small scale industries the pipe or wires cutting operation is done by manual operation. During manual cutting the chip formation is high also there may be ac cutting of the pipe. These cross cutting occurs thanks to the tight holding of the pipe. Such that to avoid these kinds of difficulties the pipe cutting operation is done by automated systems. The working of the system is to carry out two processes feeding and then cutting. The chief work of this technique is to slice out huge number of jobs in pipe form rendering to the batch production. Automation in the modern world is inevitable. The pipe/wire material feeding and cutting machine works with the help of motor assembly and cutting assembly with controlling unit. The proposed machine is very easy to use small in size, therefore easy for mobile/moving.
\end{abstract}

Keywords: Automation, Arduino-nano, Servo Motor, Onboard Microcontroller, Stepper motor and gear assembly, Pipe Cutting

\section{INTRODUCTION}

Today engineers are finding many ways to reduce human efforts which ultimately save labor cost and valuable time. Raw materials to be used, it is necessary to cut them and then take for further operations. Therefore this cutting machine is proposed for raw materials like Pipes and wires as per requirements.

This project aims to eliminate major human errors in small diameter insulation pipe or wire cutting processes. Currently the available concept in market is focused on precise paper cutting; its horizon can be broadened over a wide range of products. Moreover, this automation assembly over any manual paper cutting machine thus is saving your capital of buying an entire new product. Unlike most automation processes, this won't replace any human from his job; rather make his life easier with speedy processes. All the operator needs to do is enter the desired length of paper, and the machine does its task of moving the sheet accurately under the blade. Here's a simple automated process applied on the cutting machine of most relevant product around us.

\section{RELATED WORK}

\author{
2.1 "Design And Fabrication Of Low Cost Portable Laser \\ Cutting Machine, Proceedings of 12th IRF International \\ Conference, Bengaluru, India, 17th May 2015", [1],
}

The objective is to style and develop a laser cutting machine which is portable and economical. The machine is meant to be highly precise, compact and straightforward to work. Due to high costing of Laser Cutters, the small scale industries can't afford it. But by the arrival of the Portable Laser Cutter, this is often made available to the tiny scale industries also. This can bring about a revolution in today's technology related to manufacturing and production. Also, any immediate production of a sophisticated design/pattern might be achieved by this. Laser-bot can be use as an alternative and possible better way for high costing Laser Cutters which currently available in the market and also it is intended to increase the use of laser cutting technology by making it cost-effective to common man. So it can be used in its applications such as Interior Designing, Carpentry, Medical Technology, and also providing aid in areas such as Army, Defence etc., wall tattooing and for other hobbyist uses.

\section{2 "Design And Fabrication Of PLC Based Paper Cutting Machine, IJARIIE 2019”[2]}

In this paper author use chart paper as a cutter for cutting operation. This project can reduce the man work and the fabrication effect and also reduce the effect of noise at the time cutting operation. The paper roll cutting machine the principal of paper cutting utilized in industrial application. According to the sort of fabric to be cut, the cutter are often changed. This machine are often widely applied in most sort of industries.

\section{3 "Automatic Pipe Feeding and Cutting Machine" $[3]$}

For the purpose of reducing human effort for repetitive work of cutter pieces of pipes as well as providing a convenient fixture to support and hold the pipes/rods during cutting. The subject is considered as a part of B.E mechanical project. It can be termed as advanced machine. There are many industrial applications where differing types of pipes are required to be operated on different machines to form machine components like Shafts, Bolts, Screws, etc. This needs one and more number of pieces to be cut for mass production. The bar feeding mechanism may be a metal cutting machine designed to feed the metal. The 


\section{International Journal of Engineering Applied Sciences and Technology, 2020 Vol. 5, Issue 1, ISSN No. 2455-2143, Pages 454-456 \\ Published Online May 2020 in IJEAST (http://www.ijeast.com)}

structure is exclusively intended for the mass production and they shows faster and more efficient way to feed the metal. The clamping arrangement can be changes according to need of operations suitable. The total structure is compact in size, light weight, modular and flexible to be used in small works jobs which needs batch production. The system even has the potential to feature up a PLC system to regulate its overall working with ease and with less effort provided.

\section{4 "Automatic Pipe Cutting Machine"[4]}

The bar feeding mechanism may be a metal cutting machine designed to feed the metal. The machine is exclusively intended for the productipotentialon and that they represent faster and more efficient thanks to feed the metal. In this project we are designing and developing automatic pipe cutting machine which will be useful to feed the bar to the cutter automatically and then cutting the same.

\section{PROPOSED SYSTEM METHODOLOGY}

The fundamental topic of this task is feed the raw material, get data, cut the wire/pipe as per requirements. For this, stepper motor assembly is used draw the wire or pipe for desired length. Microcontroller incites the servo engine by giving the controlled sign. All the while, the microcontroller sends the information to the Liquid Crystal show to show and it offers the capacity to LEDs to demonstrate the work status.

The pipe/wire holder is nothing but the gear and pully assembly used to drawn the pipe or wire for cutting. Initially, the operator will need to specify the parameters such as length, quantity etc. Also, it can be pre-defined if the parameters are fixed as per the requirements. Once the raw data entered then the system will start the functioning as per data and instructions provided. The stepper motor and pipe/wire holder assembly will fetch the pipe or wire towards the cutting assembly. The tightness of the holder assembly is an advantage to pull the pipe or wire straightly. It will also minimize the occurrence of error due to unequal cutting edges.

Further, the controlling unit and stepper motor will pull the required length of pipe towards the cutter assembly. The Cutter assembly is the cutter controlled by the servo motor. The Servo motor is attached to blade or cutter to cut the pipe or wire perfectly and then it will reinstate itself for next cut. The synchronization between pulling and cutting assembly is an advantage and results the perfect and quality cutting machine with the fast speed.

The LCD shows the current status of ongoing work. The LCD will helps operator to know the progress of task and then the operator can manage the other dependent resources. The display shows the quantity yet to cut and the work done status.

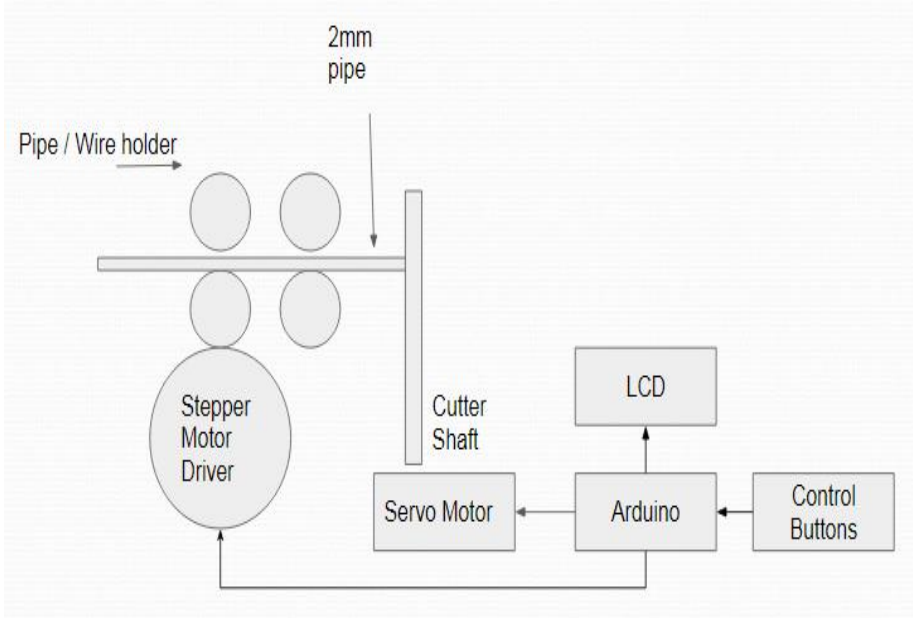

Figure 1: Assembly diagram of Proposed system

Figure 1 shows the assembly or structured diagram of the proposed system. The Arduino Nano board is used as a controller board. The control buttons and other peripherals are interfaced with the board. The unit comprises the motor gear assembly which is driven by an electric engine.

\section{FLOWCHART OF PROPOSED SYSTEM}

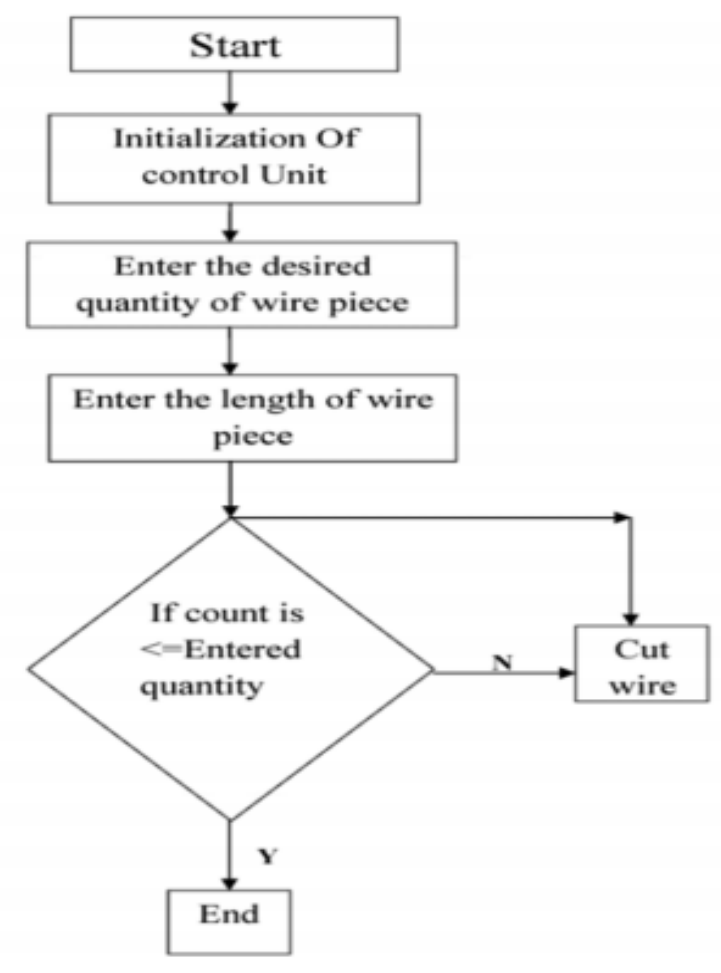

Figure 2: Flowchart of proposed system 


\section{International Journal of Engineering Applied Sciences and Technology, 2020 \\ Vol. 5, Issue 1, ISSN No. 2455-2143, Pages 454-456 \\ Published Online May 2020 in IJEAST (http://www.ijeast.com)}

The work-flow for system is as described in Figure 2. The system initialization starts with the control unit initialization. Further the system needs data such as quantity and the length of wire piece. Then system starts with cutting of wire as per the given data. Once the system done with the desired quantity it stop.

\section{SYSTEM EXPERIMENTATION AND PRACTICAL IMPLEMENTATION}

The discussed system is implemented on small size Basics implemented system is as shown in figure 3 below.

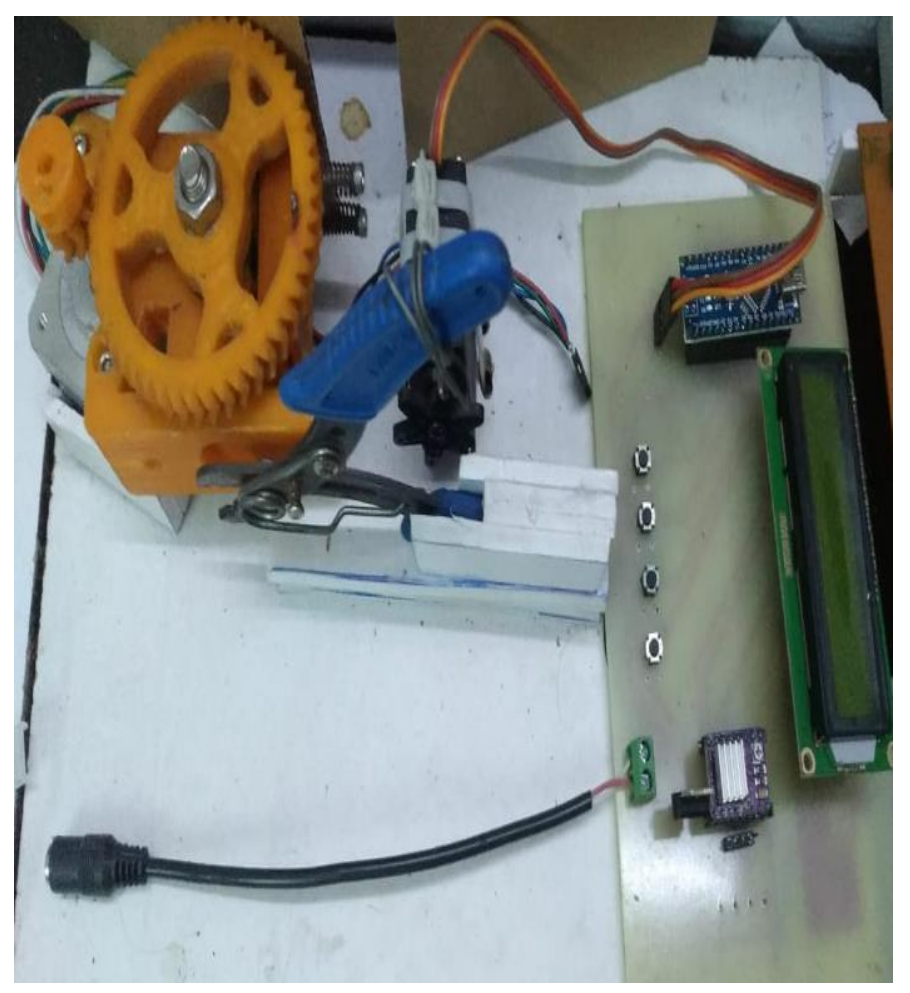

Figure 3: Experimental setup of proposed system

\section{CONCLUSION}

Automatic pipe/wire slicing machine is fundamentally valuable for arranging the items in the business explicitly enormous scope enterprises where large scale manufacturing is done. The machine additionally lessens the endeavors of the laborers by decreasing the time spent on material dealing with. The application region of this machine is extremely wide in enterprises where automation is assembled. We have proposed a framework that would expand the creation rate and exactness of material dealing with the framework. The framework would isolate objects dependent on their shading and weight according to necessity by the client. What's more, we can adjust the framework as indicated by the necessity. In order to demonstrate the application of the system, this paper is designed. This system cuts the wire according to the provided data, which results in upgrading the automation in the industries. Also it reduces the human efforts and error rate in production and loss for industries.

\section{REFERENCES}

[1] Ravi Kumar R, Megharaj N S. (2015). "Design And Fabrication Of Low Cost Portable Laser Cutting Machine", 12th IRF International Conference, Bengaluru, India, 17th May 2015

[2] Kumaresan.C, Elango.M, Jagadhesan.R, (2019).,"Design And Fabrication Of PLC Based Paper Cutting Machine”, Vol-3 Issue-3 2017, IJARIIE 2019

[3] Mr. Jagtap Sameer, Mr. Jaunjal Akash, (2019)., "Automatic Pipe Feeding and Cutting Machine", IJSRD International Journal for Scientific Research \& Development| Vol. 7, Issue 02, 2019

[4] Prof. P.D. Menghani, Akarsh Jaiswal, (2017).,“Automatic Pipe Cutting Machine", International Conference on Ideas, Impact and Innovation in Mechanical Engineering (ICIIIME 2017), Volume: 5 Issue: 6

[5] Tony Thomas. A, Muthu Krishnan.A, Sre. Nandha Guhan. (2014).,"Design And Development Of Automated Vegetable Cutting Machine", 5th International \& 26th All India Manufacturing Technology, Design and Research Conference (AIMTDR 2014) December 12th-14th, 2014, IIT Guwahati, Assam, India.

[6] P. Balashanmugam , G. Balashanmugam. (2015).," Design and Fabrication of Typical Pipe Cutting Machine". Journal Of Mechanical And Civil Engineering (IJRDO) Volume1, Issue5,feb 2015 ISSN: 2456-1479.

[7] Rushikesh Gadale, Mahendra Pisal, Sanchit Tayade, S.V.Kulkarni, 'PLC based Automatic Cutting Machine'.

[8] G.Arundeesh, R.Rathish, Logeshwaran, N.Maniraj, V.Poovarasan 'Design and fabrication of paper cutting machine'.

[9] R.Ragavendiran, C.Magesh kumar, A.Sarath, M.Mohan Babu 'Design and fabrication of automatic Paper Cutting machine'. 